\title{
Age And Sex Matched Data- Two Ears Improved Social Interaction And Quality Of Life
}

\author{
Sanem Okșan ERKAN, MD - Birgül TUHANIOĞLU, MD² \\ 1 Health Science University, Adana City Education and Research Hospital, \\ Department of Otorhinolaryngology and Head and Neck Surgery, Adana,TURKEY \\ Orchid-ID:0000-0001-5900-520X \\ 2 Health Science University, Adana City Education and Research Hospital, \\ Department of Otorhinolaryngology and Head and Neck Surgery, Adana,TURKEY \\ Orchid-ID: 0000-0001-6566-843X
}

\begin{abstract}
Introduction: Hearing aids are electronic devices used by individuals with hearing loss to improve their quality of life. It is more useful to use bilateral hearing aids. Thus, the localization of the sound is better determined and an additional 6-10 dB increase in sound intensity can be achieved. In our study, we compared the satisfaction level of patients with hearing loss who used unilateral or bilateral devices.
\end{abstract}

Methods: Patients with bilateral sensorineural hearing loss and using unilateral or bilateral hearing aids for at least 3 months and whose hearing loss cannot be treated with medical or surgical treatments were included. International Outcome Inventory for Hearing Aids Turkish Version (IOIHA-TR) was administered to them.
Results: Matched data were used to standardize age and gender between the groups. In high school bilateral fitting increased. There was no difference between the groups in terms of hearing pure tone thresholds and speech discriminations. There was a significant difference between the groups in terms of the mean score of question $5(p=0.047)$, question $7(p=0.022)$ and mean total scale $(p=0.028)$ in IOI-HA-TR.

Conclusion: As a result, we found that the satisfaction level of bilateral hearing aid users was higher. Bilateral hearing aid use has a positive effect on the social life of patients and increases their quality of life.

Keywords: sensorineural hearing loss, hearing aids, quality of life

aids are electronic devices used by individuals with hearing loss to improve their quality of life. Various instruments have been produced for hearing throughout history. The use of hearing aids improves both auditory perception and quality of life. ${ }^{[1]}$ A good evaluation is needed to decide to whom a hearing aid will be given and to which ear a hearing aid will be installed. Patients who can be medically or surgically treated should be detailed in a careful process
Correspondence: Sanem Okşan ERKAN, MD Health Science University, Adana City Education and Research Hospital, Department of Otorhinolaryngology and Head and Neck Surgery, Adana, TURKEY

e-mail: sanemyilmaz67@yahoo.com

Received: 28.05.2019; Accepted: 08.07.2019
Online available at: www.entupdates.org 
and should be treated in an appropriate way before they are given a hearing aid. In the past, hearing aids were recommended to adult patients with hearing of more than 40 $\mathrm{dB}$ as moderate hearing loss. If the patient had hearing $>80$ $\mathrm{dB}$, it was thought that the amplifier would be difficult to tolerate. However, in recent years, the Communique on Health Care rules have changed and the indications for the delivery of aids and the payment status of the Social Security Institution may differ by hearing level, bilateralism. Adult patients can get the hearing aid with mild hearing loss as more than $30 \mathrm{~dB}$ and speech discrimination is an important measurement that determines the benefit the patient can see. In general, if hearing loss is bilateral and symmetrical, it is more useful to use bilateral hearing aids. Thus, the localization of the sound is better determined and an additional 6-10 $\mathrm{dB}$ increase in sound intensity can be achieved. In asymmetrical hearing loss, the results can be better with bilateral use. ${ }^{[2]}$ The use of two-sided hearing aids in people with bilateral hearing loss is very useful in many respects. Better noise localization, reducing the head shadow effect, recognizing and distinguishing speech in background noise, and reducing the effect of auditory deprivation are some of these. ${ }^{[3]}$ However, the difficulty in tolerating and economic reasons can push the patient to use one-sided devices and recent studies have questioned the benefits of binaural fitting. ${ }^{[4,5]}$

Hearing loss causes depressive symptoms and decreased functional capacity and decreases the quality of life. ${ }^{[6]}$ In addition, it affects physical, cognitive, behavioral, and social functions negatively and is related with depression and dementia and reduces the overall quality of life. ${ }^{[7]}$ People with hearing loss cannot hear and understand conversations when there is background noise. They may experience tinnitus and they have trouble hearing the television. They are tired and tense due to the hearing effort. They may experience dizziness and balance problems.

When we look at studies on hearing loss, we see that few studies have investigated patient satisfaction in those using hearing aids. In our study, we compared the satisfaction level of patients with hearing loss who used unilateral or bilateral devices by using the Turkish version of the International Outcome Inventory for Hearing Aids (IOIHA TR) assessment scale, which consists of 7 questions.

\section{Methods}

Patients who were admitted to our outpatient clinic between September 2018 and October 2018 and who were followed up in our clinic and used hearing aid for 3-36 months were included in the study. The study was approved by the ethics committee of the University of Health Sciences, Adana City Education Research Hospital (268/2018). The patients were briefed about the study and informed consent was received.

Demographic data (age, gender, education level) were obtained by taking detailed anamnesis from the patients. In addition, full ear, nose, and throat examinations were performed and audiometric examinations were performed by the same audiometrist. In pure tone audiogram, thresholds of hearing by air and bone conduction were measured at 500, 1000, 2000, 4000 Hertz and speech discrimination with monosyllabic words were measured using an audiometer device Pc Clinical Audiometry/otometrics/Madsen Astrera 2. After taking an anamnesis and completing examinations, patients between 18-85 years, with no psychiatric disorder, with no ear surgery history, with intact tympanic membranes, with bilateral sensorineural hearing loss and using unilateral or bilateral hearing aids for at least 3 months, greatest 36 months and patients whose hearing loss cannot be treated with medical or surgical treatments were contacted in the outpatient clinic and the IOI-HA TR scale was administered to them (Table 1). The IOIHA TR consists of 7 questions and the higher the score, the higher the patient satisfaction. The reliability of the Turkish version has been demonstrated in the study of Kırkım et al [8] There are five options for each question, and each question is scored between 1-5. The sum of these scores were recorded. In our study, the satisfaction level of the patients using unilateral and bilateral aids was compared with the demographic data.

\section{Statistical analyses:}

The data were analyzed using the IBM Statistical Package for the Social Sciences (SPSS) Version 21.0 package program. Age and sex were matched in a 1:1 ratio using the propensity score method to provide homogeneity between the groups. The normality of the matched data was tested using the Shapiro-Wilk test. Student's t-test was used to compare the means of two independent groups with normal distribution, and the Mann-Whitney $\mathrm{U}$ test was used to compare the medians of two independent groups without normal distribution. Descriptive statistics were expressed as mean, standard deviation, median, $25-75 \%$ quartiles, and minimum and maximum values. The Chi-square test was used to analyze categorical data. In the event of the presen- 


\section{International Outcome Inventory for Hearing Aids -Turkish Version (IOI-HA-TR)}

1- Think about how many hours you used your present hearing aid(s) over the past 2 weeks?
None (1)
Less than 1 hour a day (2)
1-4 hours a day (3)
4-8 hours a day (4)
More than 8 hours a day (5)

2- Think about the situation where you most wanted to hear better before you got your present hearing aid(s). Over the past 2 weeks ,how much has the hearing aid helped in that situation?
Helped not at all (1)
Helped slightly (2)
Helped moderately (3)
Helped quite a lot (4)
Helped very much (5)

3- Think again about the situation where you most wanted to hear better.Over the past 2 weeks, when you use your present hearing aid(s), how much difficulty do you still have in that situation?
Very much difficulty (1)
Quite alot difficulty (2)
Moderate difficulty (3)
Slight difficulty (4)
No difficulty (5)

4- Considering everything, do you think your present hearing aid(s) is worth the trouble?
Not at all worth it (1)
Slightly worth it (2)
Mildly worth it (3)
Moderately worth it (4)
Completely worth it (5)

5- Over the past 2 weeks, with your present hearing aid(s), how much have your hearing difficulties affected the things you can do?
Affected very much (1)
Affected quite a lot (2)
Affected moderately (3)
Affected slightly (4)
Affected not at all (5)

6- Over the past 2 weeks, with your present hearing aid(s), how much do you think other people were bothered by your hearing difficulties?
Bothered very much (1)
Bothered quite a lot (2)
Bothered moderately (3)
Bothered slightly (4)
Bothered not at all (5)

7- Considering everything, how much has your present hearing aid(s) changed your enjoyment of life?
Worse (1)
No change (2)
Slightly better (3)
Quite a lot better (4)
Very much better (5)

ce of significance in data with $>2$ categories, "comparison between two rates" was used.Descriptive statistics are expressed as frequency and percentage. Statistical significance level was taken as 0.05 for all analyses.

\section{Results}

Matched data were used to standardize age and sex be- tween the groups. There was no significant difference between the mean age of patients using unilateral and bilateral aids ( $\mathrm{p}=0.098)$ (Table 2). The distribution of sex between the groups was homogenous $(\mathrm{p}=0.463)$. Education levels were not homogeneously distributed between the groups $(\mathrm{p}=0.002)$. There was a significant difference between the groups with secondary and high school educa- 


\begin{tabular}{lccccc}
\hline \multicolumn{2}{l}{ Table 2: Mean age values in the groups } & & & \\
\hline & Group & N & Mean \pm SD & Min & Max \\
Age & 60 & $50.23 \pm 22.52$ & 18 & 85 & 8.098 \\
& Bilateral & 60 & $55.95 \pm 13.95$ & 18 & 84 \\
\hline
\end{tabular}

p: Student's t-test, SD: standard deviation

\begin{tabular}{|c|c|c|c|c|c|c|c|}
\hline & & & & & & & $P$ \\
\hline & Frequency & $\%$ & Frequency & $\%$ & Frequency & $\%$ & \\
\hline \multicolumn{8}{|l|}{ Sex } \\
\hline Female & 25 & 41.7 & 29 & 48.3 & 54 & 45.0 & \multirow{2}{*}{0.463} \\
\hline Male & 35 & 58.3 & 31 & 51.7 & 66 & 55.0 & \\
\hline \multicolumn{8}{|l|}{ Education } \\
\hline Primary & 9 & 15.0 & 17 & 29.3 & 26 & 22.0 & \multirow{3}{*}{0.002} \\
\hline Secondary & 4 & 6.7 & 15 & 25.9 & 19 & 16.1 & \\
\hline High & 28 & 46.7 & 16 & 27.6 & 44 & 37.3 & \\
\hline University & 19 & 31.7 & 10 & 17.2 & 29 & 24.6 & \\
\hline \multicolumn{8}{|c|}{ Ear Back/Inside } \\
\hline Back & 39 & 65.0 & 33 & 55.0 & 72 & 60.0 & \multirow{2}{*}{0.264} \\
\hline Inside & 21 & 35.0 & 27 & 45.0 & 48 & 40.0 & \\
\hline
\end{tabular}

p: Chi-square test

tion in terms of bilateral or unilateral aid use, respectively $(p=0.005, p=0.032)$. In secondary school unilateral, in high school bilateral fitting increased. There was no significant difference between the groups in terms of inner ear and behind-ear aid use $(p=0.264)$ (Table 3). There was no difference between the groups in terms of median duration of device use $(\mathrm{p}=0.082)$. Minimum of 3 months and more than 36 months hearing aid usage were initially eliminated (Table 4). There was no difference between the groups in terms of hearing pure tone thresholds and speech discriminations(Table 5). There was a significant difference between the groups in terms of the mean score of question $5(\mathrm{p}=0.047)$ and question $7(\mathrm{p}=0.022)$. There was a significant difference between the groups in terms of the mean total scale $(\mathrm{p}=0.028)$. The satisfaction level of

\begin{tabular}{lllll}
\hline \multicolumn{4}{l}{ Table 4: Duration of device use in the groups } \\
$\begin{array}{l}\text { Duration of device } \\
\text { use }\end{array}$ & Median & Q1-Q1 & Min-Max & p \\
\hline Bilateral & 12 & $6-24$ & $3-36$ & 0.082 \\
Unilateral & 11.5 & $5-18$ & $3-36$ & \\
Total & 12 & $6-24$ & $3-36$ & \\
\hline
\end{tabular}

p: Mann-Whitney $U$ test

teral devices was higher in terms of social competence and quality of life (Table 6)(Figure 1). 


\begin{tabular}{|c|c|c|c|c|c|}
\hline & Group & Mean \pm SD & Min & Max & $\mathbf{P}$ \\
\hline \multirow{3}{*}{$\begin{array}{l}\text { Right } \\
\text { pure tone } \\
\text { thresholds }\end{array}$} & Bilateral & $61.32 \pm 14.34$ & 35 & 102 & \multirow{2}{*}{0.366} \\
\hline & Unilateral & $58.95 \pm 14.20$ & 24 & 86 & \\
\hline & Total & $60.13 \pm 14.26$ & 24 & 102 & \multirow{4}{*}{0.526} \\
\hline \multirow{3}{*}{$\begin{array}{l}\text { Left pure } \\
\text { tone } \\
\text { thresholds }\end{array}$} & Bilateral & $60.50 \pm 15.05$ & 30 & 93 & \\
\hline & Unilateral & $58.57 \pm 18.08$ & 20 & 115 & \\
\hline & Total & $59.47 \pm 16.40$ & 20 & 115 & \\
\hline \multirow{3}{*}{$\begin{array}{l}\text { Right } \\
\text { speech } \\
\text { discrimina- } \\
\text { tion }\end{array}$} & Bilateral & $67.97 \pm 17.49$ & 16 & 96 & \multirow{2}{*}{0.835} \\
\hline & Unilateral & $68.60 \pm 15.76$ & 28 & 96 & \\
\hline & Total & $68.28 \pm 16.58$ & 16 & 96 & \multirow{4}{*}{0.767} \\
\hline \multirow{3}{*}{$\begin{array}{l}\text { Left } \\
\text { speech } \\
\text { discrimina- } \\
\text { tion }\end{array}$} & Bilateral & $67.58 \pm 16.60$ & 28 & 92 & \\
\hline & Unilateral & $66.58 \pm 20.05$ & 0 & 100 & \\
\hline & Total & $68.08 \pm 18.33$ & 0 & 100 & \\
\hline
\end{tabular}

p: Student's t-test, SD: standard deviation

\section{Discussion}

In this study, validity-reliability analyses were made and satisfaction level of patients using hearing aids were evaluated with the Turkish version of the IOI-HA scale, which has been used in various studies, and the relationship between age, sex, education level, audiogram values, and IOI-HA inventory scores were investigated. In order to standardize the demographic data, age- and sex-matched patients were used in the groups. Although different periods were used to evaluate satisfaction questionnaires in the literature, this study was based on follow-up for 3 months after the use of the aid because the experience was stabilized and the quality of life scores did not change after the first 3 months with the use of the aid. ${ }^{[9,10]}$

Hearing aids that can be implanted into bone and cochlear implants instead of handheld hearing aids have been used frequently in recent years. These are preferred in younger patients; older patients still retain the popularity of handheld hearing aids because they do not require surgery.

With bilateral hearing loss, bilateral hearing aids are required. ${ }^{[11]}$ If unilateral amplification will be preferred in patients with bilateral hearing loss, there are criteria of choice for which ear to be preferred. The side with a higher speech discrimination score, wider dynamic range, mean pure tone near $60 \mathrm{~dB} H \mathrm{HL}$, and flat audiogram without outer or middle ear problems is chosen. In addition, the domi-

Table 6: Scores in questions one by one and totally, according to the IOI-HA scale in the groups

\begin{tabular}{|c|c|c|c|c|c|c|c|}
\hline & \multicolumn{3}{|c|}{ Bilateral } & \multicolumn{3}{|c|}{ Unilateral } & \multirow[b]{2}{*}{$p$} \\
\hline & Mean \pm SD & Min & Max & Mean \pm SD & Min & Max & \\
\hline Question 1 & $4.85 \pm 0.40$ & 3 & 5 & $4.82 \pm 0.52$ & 3 & 5 & 0.121 \\
\hline Question 2 & $4.15 \pm 0.84$ & 2 & 5 & $3.92 \pm 0.72$ & 2 & 5 & 0.105 \\
\hline Question 3 & $4.05 \pm 0.72$ & 3 & 5 & $3.80 \pm 0.80$ & 2 & 5 & 0.075 \\
\hline Question 4 & $4.50 \pm 0.70$ & 2 & 5 & $4.42 \pm 0.81$ & 1 & 5 & 0.548 \\
\hline Question 5 & $4.28 \pm 0.76$ & 2 & 5 & $3.98 \pm 0.87$ & 1 & 5 & 0.047 \\
\hline Question 6 & $4.42 \pm 0.77$ & 2 & 5 & $4.18 \pm 0.85$ & 1 & 5 & 0.118 \\
\hline Question 7 & $4.38 \pm 0.76$ & 2 & 5 & $4.05 \pm 0.81$ & 1 & 5 & 0.022 \\
\hline Total & $30.63 \pm 3.66$ & 18 & 35 & $29.07 \pm 4.05$ & 12 & 35 & 0.028 \\
\hline
\end{tabular}


nant side or request of the patient should be considered. ${ }^{[8]}$ Objective analysis of the performance of the hearing aid should be performed and the gain with using the aid should be measured and evaluated. ${ }^{[12]}$

Many inventories such as the Abbreviated Profile of Hearing Aid Benefit (ABHAB), Client- Oriented Scale of Improvement (COSI), Glasgow Hearing Aid Benefit Profile (GHABP), Satisfaction with Amplification in Daily Life (SADL), and the IOI-HA are used to evaluate satisfaction of hearing aid use. They are used to measure the satisfaction of patients and assess the effect of aids on quality of life and to solve the distressing situations of the patients by monitoring them. In our study, we used the Turkish version of the IOI-HA scale, which has proven reliability.

IOI-HA consists of questions that measure the daily use of the aid, the benefits obtained, residual activity limitation, satisfaction, residual participation limitation, impact on other people, and quality of life. In general, scores $\leq 3$ show that the hearing aid rehabilitation is inadequate. ${ }^{[13]} \mathrm{McPherson}$ and Wong evaluated 19 patients aged 62-83 years after 3 months of hearing aid use. The mean IOIHA scale score was $3.82 \pm 0.60$. Fifty-three percent of the participants used an aid for $1-4$ hours, $15.8 \%$ for $4-8$ hours, and $15.8 \%$ for more than 8 hours. Eighteen participants reported that the hearing aid was useful, $53 \%$ had no residual activity limitation when using the hearing aid, all participants were satisfied with the hearing aid, $37 \%$ had no residual participation limitation, $74 \%$ of the patients' relatives reported that they were not affected by the problems caused by hearing loss of the patients while they were using a hearing aid, and 17 participants reported that using a hearing aid positively affected their quality of life. ${ }^{[14]}$ In the study of Kırkım et al, according to data obtained 12 months after the acquisition of a hearing aid, $10.9 \%$ of patients did not use the device, $4.7 \%$ used them less than 1 hour per day, $16.3 \%$ used them 1-4 hours per day, $11.5 \%$ used them $4-8$ hours per day, and $56.6 \%$ used them more than 8 hours per day. ${ }^{[8]}$ In the study of Cox et al., the mean IOI-HA scores were between 3.5 and 4.1 in patients who were followed up for 6-12 months. In the study of Saatç1 et al, the mean IOI-HA score was $4.12 \pm 0.78$. It was reported that $60 \%$ of the participants used a hearing aid more than 8 hours per day, 20\% used them for $4-8$ hours, $10 \%$ used them for $1-4$ hours, and $10 \%$ used them less than 1 hour per day. Their findings were as follows: $90 \%$ of patients had moderate or more benefit from their hearing aid, $5 \%$ still had distress in places where they most wanted to hear, $80 \%$ were satisfied with hearing aid at a level of mode- rate or above, $5 \%$ reported that hearing loss negatively affected their work while they were using a hearing aid, none of the patients' relatives reported that they were affected by the problems caused by hearing loss of the patients while they were using a hearing aid, and $85 \%$ reported that hearing aids positively affected their quality of life. ${ }^{[15]}$ In these studies, the satisfaction level of the patients with hearing aids was measured. We aimed to compare the satisfaction level of patients using unilateral and bilateral aids. It's known that when hearing loss occurs in both ears, the use of binaural hearing aids is generally advised because of the reason of best location of sound, binaural summation, elimination of the head shadow effect, ability to distinguish sounds from background noise and better speech recognition of noise. ${ }^{[16-18]}$ Binaural fitting is preferable for all individuals unless there is a particular contradiction or the patient is happy to use one hearing aid only. On the other hand there are some studies that reported $\% 71^{[4]}$ and $\% 46{ }^{[5]}$ speech performance with monoaural fitting, the patients adapted better to using monoaural aids and binaural fitting is not the best choice. In order to check whether or not good results are provided, initial assessment of the best performance is so important with binaural fitting.

When we evaluated the 7 questions separately, the highest score was found in the first question in both groups, which was related with the duration of hearing aid use. The mean duration of usage was more than 8 hours that the mean value of 1 .question was $4.85 \pm 0.40$ years in unilateral users and $4.82 \pm 0.52$ years in bilateral users. The high rate of longterm use of hearing aid throughout the day in the patient group can be associated with the ergonomic and functional innovations that hearing aids provide in accordance with technological developments. Although there was no significant difference between the two groups in terms of the mean scores of question 2, which measures the benefit obtained from the hearing aid, the satisfaction level of both groups was higher than 3.5 , and it tended to be higher in bilateral hearing aid users. There were no significant differences between the two groups in terms of the mean scores of question 3 , which measures activity restriction, and question 4, which measures satisfaction levels, but scores were higher among bilateral hearing aid users. The fifth question measures social competence and the majority of the patients using hearing aids reported that they benefited from hearing aids in their social and work lives. There was a statistically significant difference between the groups in terms of mean score of the fifth question in favor of the bilateral 
hearing aid users. There was no significant difference between the two groups in terms of the mean scores of question 6, which measures the impact on other people in the vicinity. The mean score of the seventh question, which measures how hearing aids affect quality of life, was statistically significantly higher in bilateral hearing aid users than in unilateral hearing aid users, which means bilateral users enjoyed life more.

\section{Conclusion}

As a result, we found that the satisfaction level of bilateral hearing aid users was higher. Bilateral hearing aid use has a positive effect on the social life of patients and increases their quality of life. Patients with bilateral hearing loss should be encouraged to use bilateral hearing aids to increase the degree of satisfaction expected from their aids. Hereafter six months waiting period would be resolved by the Communique on Health Care. We think that future studies with more patients with hearing loss and studies in which patients are grouped according to hearing loss levels and speech thresholds will contribute to the literature.

\section{Acknowledgement:}

We would like to thank Asena Ayça Özdemir for her help in the statistical analyses. 


\section{References}

1. Kahveci OK, Miman MC, Okur E, Ayçiçek A, Sevinç S, Altuntaş A. Hearing aid use and patient satisfaction. [Article in Turkish] Kulak Burun Boğaz Ihtis Derg 2011;21:117-21.

2. Boymans MS, Goverts T, Kramer SE, Festen JM, Dreschler WA. A prospective multi-centre study of the benefits of bilateral hearing. Ear Hear 2008;29:930-41.

3. SilmanS, Gelfand SA, Silverman CA. Late-onset auditory deprivation: effects of monaural versusu binaural hearing aids. J Acoust Soc Am 1984;76:1357-62.

4. Henkin Y, Waldman A, Kishon-Rabin L. The benefits of bilateral versus unilateral amplification for the elderly: are two always better than one? J Basic Clin Physiol Pharmacol 2007;18:201-16.

5. Cox RM, Schartz KS, Noe CM, Alexander GV. Preference for one or two hearing AIDS among adult patients. Ear Hear 2011;32:81-197.

6. Lupsakko TA, Kautiainen HJ, Sulkava R. The nonuse of hearing aids in people aged 75 years and over in the city of Kuopio in Finland. Eur Arch Otorhinolaryngol 2005;262:165-9.

7. Arlinger S. Negative consequences of uncorrected hearing loss-a review. Int J Audiol 2003;42:17-20.

8. Kırkım G, Şerbetçioğlu MB, Mutlu B. Assessment of Patient Satisfaction for Hearing Aids Using the Turkish Version of International Outcome Inventory for Hearing Aids. [Article in Turkish] KBB ve BBC Dergisi 2008;16:101-7.
9. Crandell C. Hearing aids: their effects of functional health status. Hear J 1998;51:22-32.

10. Stark P, Hickson L. Outcomes of hearing aid fitting for older people with hearing impairment and their significant others. Int J Audiol 2004;43:390-8.

11. Cohen-Mansfield AJ, Infeld DL. Hearing aids for nursing home residents: Current policy and future needs. Health Policy 2006;79:49-56.

12. Özgürsoy OB, Küçük B. Objective analysis of hearing aids performance. [Article in Turkish] Turk Geriatri Derg 2007;10:69-72.

13. Cox RM, Alexander GC, Beyer CM. Norms for the International Outcome Inventory for Hearing Aids. J Am Acad Audiol 2003;14:403-13.

14. McPherson B, Alexander GC. Effectiveness of an affordable hearing aid with elderly persons. Disabil Rehabil 2005;27:601-9.

15. Saatcı Ö, Polat B. Hearing loss and satisfaction of hearing aid impact on quality of life in geriatric population. KBB-Forum 2016;15(4).

16. Köbler S, Lindblad AC, Olofsson A, Hagerman B. Successful and unsuccessful users of bilateral amplification: Difference and similarities in binaural performance. Int J Audiol 2010;49:613-27.

17. Akeroyd MA. The psychoacoustics of binaural hearing. Int J Audiol 2006;45:25-33.

18. Hawkins DB, Prosek RA, Walden BE, Montgomery AA. Binaural loudness summation in the hearing impaired. J Speech Hear Res 1987;30:37-43.

This is an open access article distributed under the terms of the Creative Commons Attribution-NonCommercial-NoDerivs 3.0 Unported (CC BY- NC-ND3.0) Licence (http://creativecommons.org/licenses/by-nc-nd/3.0/) which permits unrestricted noncommercial use, distribution, and reproduc- tion in any medium. provided the original work is properly cited.

Please cite this article as: Okşan Erkan S, Tuhanıoğlu B. Age And Sex Matched Data- Two Ears Improved Social Interaction And Quality Of Life. ENT Updates 2019;9(2): 90-97. 